\title{
Surgical interventions for the treatment of
}

\author{
sacroccocygeal pilonidal sinus disease in
}

\section{children: A systematic review and meta-}

\section{analysis}

Hardy EJO ${ }^{1,2}$, Herrod PJJ1,2, Doleman $\mathrm{B}^{2}$, Phillips $\mathrm{HG}^{2}$, Ranat $\mathrm{R}^{2}$, Lund $\mathrm{JN}^{1,2}$

1. Department of General Surgery, Royal Derby Hospital, Derby, UK DE22 3NE

2. Department of Surgery, Division of Medical Sciences and Graduate Entry Medicine, University of Nottingham, Derby, DE22 2DT

Funding: This research did not receive any specific grant from funding agencies in the public, commercial, or not-for-profit sectors.

Conflicts of interest: None

Correspondence to:

Mr E Hardy

Department of Surgery,

Royal Derby Hospital,

Derby,

United Kingdom,

DE22 3NE

(+44)01332 724905

edward.hardy@nhs.net

Abstract Word Count: 369

Word Count: 4119

Number of figures: 12

Number of supplementary digital content files: 12 


\section{Abstract}

\section{Background}

Pilonidal sinus disease (PNS) is not uncommon in children. Controversy remains over the best treatment and there is limited evidence. This systematic review and meta-analysis aims to establish which techniques have the best outcomes in children.

\section{Methods}

MEDLINE, EMBASE and CENTRAL databases were searched. Studies reporting treatment outcomes for PNS in children were included.

\section{Results}

Open healing has pooled risk of recurrence of $26 \%(95 \% \mathrm{Cl} 15-38 \%)$, risk of wound complication of $21 \%(9-36 \%)$ and wound healing ranged from 38-92 days. Midline primary closure has pooled risk of recurrence of $12 \%$ (8-18\%), risk of wound complication of $30 \%$ (19-46\%) and wound healing ranged from 8-32 days. Off-midline primary closure has pooled risk of recurrence of $6 \%(1-15 \%)$, risk of wound complication of $14 \%(6-25 \%)$ and wound healing was 27 days. VAC therapy has pooled risk of recurrence of $20 \%(0-65 \%)$ and wound healing ranged from 38-92 days. Minimally invasive techniques has pooled risk of recurrence of $7 \%(1-16 \%)$ and wound healing ranged from 21-30 days. Marsupialisation has pooled risk of recurrence of $6 \%(0-22 \%)$, and wound healing ranged from 6-41 days.

\section{Conclusion}

Evidence for management of PNS in children is poor. Off-midline primary closure, minimally invasive techniques, and marsupialisation have the best outcomes.

\section{KEYWORDS}

Pilonidal Sinus, Adolescent, Child, Systematic Review, Surgery

Level of Evidence rating: IV 


\section{Introduction}

Sacrococcygeal pilonidal sinus disease (PNS) ${ }^{1}$ is not uncommon in children [1,2]. Onset is usually around the time of puberty. Symptoms such as recurrent acute abscess and chronic suppuration may have significant impact on patients' quality of life [4], education and social integration $[2,3]$. The ideal treatment for this condition should cause minimal disruption or discomfort whilst having good cure and recurrence rates.

Systematic reviews and meta-analyses $[4,5]$ in the treatment of adult PNS have indicated wide excision and healing by secondary intention has the lowest long term recurrence, whilst excision with primary closure via an off-midline or flap technique have quicker healing and only slightly less favourable recurrence rates. These approaches involve significant tissue loss, a hospital admission often of several days[2] and a long time (14-60 days) until return to normal activities $[6,7]$.

More recently minimally invasive techniques including fibrin glue obliteration $[8,9]$, minimal excision [10], endoscopic [11,12] and crystallized phenol [13] and have been described in both adults and children. These treatments reportedly offer quicker healing and return to normal activities with acceptable recurrence rates. However, long term follow-up data is absent.

The treatment of PNS in children has generally mirrored that in adults, but there has been little research in in children $[1,14]$. It is not well understood whether adult outcomes can be generalised to children; indeed some studies have indicated that long term recurrence rates are higher in patients where surgery is required at an earlier age [15]. This may be due to a genetic predisposition to developing the disease, or that PNS presenting in childhood tends to be more severe or that the conditions predisposing to PNS are present for a longer period. Furthermore, as surgical interventions in children may impact on schooling, sporting

\footnotetext{
${ }^{1}$ PNS - pilonidal sinus disease
} 
activities and social integration, different outcome priorities may exist for treatment in this age group.

We have therefore carried out a systematic review and meta-analysis of all published evidence regarding the treatment of pilonidal sinus disease in the paediatric population with the aim of establishing which techniques have the best outcomes for recurrence, wound healing, wound complications, and which are most acceptable to patients. We also looked for evidence on quality of life and time to return to normal activities.

\section{Method}

\section{Study design}

This systematic review was registered prospectively with PROSPERO (registration number CRD42018095297) and was carried out in accordance with the PRISMA statement [16]. Any study reporting treatment outcomes for sacrococcygeal PNS in a population with median age of 18 or under were included. The minimum outcome reporting required for inclusion was recurrence rate. Studies which did not report treatment outcomes, reported non sacrococcygeal PNS or reported outcomes in an adult population (median age $>18$ ) were excluded.

\section{Literature search}

Literature searches were carried out by a trained Clinical Research Librarian using the following databases: MEDLINE, EMBASE and CENTRAL (all searched from their inception to 17th May 2018). No language or date restriction was applied to the searches. The Cochrane Library of Systematic Reviews was searched for relevant reviews and the abstracts from the conference proceedings of the British Society of Paediatric Surgeons for the last 10 years were searched for relevant unpublished studies. Previous systematic reviews of related topics were also searched for relevant studies. References of identified potentially relevant studies were hand-searched for further studies. Finally, all studies citing 
the identified potentially relevant primary studies identified on Google Scholar were screened for inclusion. Example search strategies can be found in Appendix A.

Abstracts were screened independently by two authors $(\mathrm{EH}$ and $\mathrm{PH})$ with the aid of Rayyan systematic review software (2016, Qatar Computing Research Institute, Doha, Qatar) [17] and considered for full text review if either author deemed them to be potentially relevant. $A$ grey literature search as described above was completed by one author (RR). Full text versions of all potentially relevant primary studies were then independently screened against the inclusion and exclusion criteria by two authors $(\mathrm{EH}$ and $\mathrm{PH})$ and agreement to inclusion reached by consensus.

\section{Data extraction}

Study characteristics and outcome data were independently extracted and verified by two authors (EH and HP). Risk of bias for included studies was assessed independently by two authors using the Risk of Bias In Non-randomized Studies - of Interventions (ROBINS-I) assessment tool [18] (EH and $\mathrm{PH})$ with any disagreement resolved by consensus.

\section{Statistical analysis}

All analyses were conducted in STATA Version 15 (StataCorp LLC, Texas). We used the metaprop user-written. Effect estimates are presented as proportions with 95\% confidence intervals $(\mathrm{Cl})$ as none of the included studies reported outcomes as time to event. Pooled estimates were calculated using the Freeman-Tukey double arcsine transformation and Cls were calculated using the exact method. We used random effects models due to the clinical heterogeneity between the included studies. Statistical heterogeneity was assessed using the $\mathrm{I}^{2}$ statistic. To assess the association between follow up time and rate of recurrence we used a maximum likelihood random effects meta-regression with the Knapp Hartung modification. To assess publication bias, if ten or more studies were included we conducted Egger's linear regression test. Due to the previously published problems with conventional 
tests for publication bias and proportion outcomes we used study size rather than standard errors on the $\mathrm{Y}$ axis [19].

\section{Results}

A total of 5128 potentially relevant abstracts were screened for inclusion, of which 2664 were unique papers. Of the 2664 unique abstracts screened, 41 studies were identified for full text review. Following full text review a further 15 studies were excluded as they either did not report recurrence rates, did not clearly report which surgical technique was used or were performed in adults. Twenty six studies were included in the qualitative synthesis and 23 in the quantitative analysis (Figure 1).

\section{Study characteristics}

The characteristics of included studies are shown in Table 1. No studies published before 2002 met the criteria for inclusion. All studies had full texts published in peer reviewed journals. All included studies were retrospective case series or cohort studies. Eleven case series reported the results of one surgical intervention alone, whilst a further 11 cohort studies compared results of 2 different interventions, and 4 papers reported the results of 3 different surgical intervention. Sample sizes ranged from 8 to 268 patients. Only 4 studies reported outcomes of over 50 patients for any one intervention, and only 3 studies included a total of over 100 patients.

All but 1 study were single centre studies. Ten studies were based in the USA, 5 studies were from Turkey, 2 from each of the UK, Israel, Italy and Canada and 1 each from Spain and Italy. Ethnicity of subjects was not reported in any study.

Median follow-up ranged from 39 days to 54 months. Nine studies reported results with a median follow up of over 12 months.

\section{Risk of bias}


Risk of bias was assessed using the ROBIN-I tool (Table 2). Fifteen studies were considered at moderate risk of bias with regard to confounding factors as they had performed no appropriate analysis to adjust for any important confounding factors. The remaining 11 studies were found to be at severe risk in this domain as they had not appropriately controlled for potentially important confounding factors and performed no appropriate statistical adjustment. Eleven studies were judged to be at moderate or severe risk of selection bias as they either did not report selection criteria or selection was based on surgical preference. Two studies were judged to be at serious risk of bias with regard to classification of intervention as they grouped several procedures together in reporting outcomes. One study was at serious risk of bias due to deviation from intended intervention as a random selection of patients receiving laser epilation in addition to the primary intervention, with no reporting of the outcomes for this subset or how these patients were distributed between the 2 groups of primary intervention. All studies were at moderate risk of bias in measurement of outcomes and reporting results as all were non-blinded studies and none had a predefined set of outcomes to be reported.

Overall sixteen studies were found to be at severe risk of bias, whilst the remaining ten studies were at moderate risk.

\section{Data synthesis}

All 26 included studies reported recurrence rates, whilst 18 reported wound complication rates, allowing these outcomes to be included in meta-analysis. Only 14 studies reported outcomes for time to wound healing and where reported it was of insufficient detail to allow further analysis. Seven studies reported a measure of patient satisfaction, but the reported measure was highly variable and no studies used any validated quality of life or patient satisfaction measure. Results are summarised in table 3.

\section{Open healing}


Six studies reported the outcomes of open healing for 191 patients. All papers were comparative cohort studies, of which 1 study compared open healing to minimally invasive techniques [12], 1 compared open healing to marsupialisation [1], 2 compared open healing to off-midline primary closure $[20,21]$ and 4 compared open healing to midline primary closure $[1,21,22]$. Overall pooled risk of recurrence (Figure 2) was $26 \%$ (95\% Cl 15-38\%). When analysed as a subgroup, studies with median follow-up of over 12 months had a pooled risk of recurrence of $32 \%$ (13-53\%). There was moderate statistical heterogeneity $\left(I^{2}=54.6 \%\right)$. Wound complications were reported by 3 studies $[12,20,21]$ and the pooled risk of wound complication was $21 \%\left(9-36 \%, I^{2}=36.1 \%\right)$ (Figure 3$)$. Average time to wound healing ranged from 38 to 92 days, but was not reported in enough detail to allow pooled analysis. Meta regression analysis, assessing the relationship between length of follow-up and incidence of recurrence, appeared to show a relationship, but this did not reach statistical significance (Fig 4). There was no statistical evidence of publication bias (Egger's test $p=0.996)$.

\section{Midline primary closure}

Sixteen studies reported the outcomes of midline primary closure for a total of 728 individuals. Five studies were case series which reported the outcome of midline primary closure alone [14,23-26]. Five comparative cohort studies compared midline primary closure to off-midline primary closure [2,8,21,27,28], 4 compared it to open healing $[1,21,22,29], 3$ compared it to minimally invasive techniques $[8,13,30]$, and 2 to marsupialisation $[1,31]$. Overall risk of recurrence was $12 \%$ (8-18\%), and in studies with over 12 months follow up pooled risk of recurrence was 13\% (4-24\%) (Figure 5). There was substantial heterogeneity between groups $\left(I^{2}=62.2 \%\right)$. Wound complications were reported by 13 studies, with a pooled risk of wound complication 30\% (19-42\%), although there was considerable heterogeneity ( $I^{2} 87.4 \%$ ) (Figure 6). Average time to wound healing was reported by 7 studies and ranged from 8 to 38 days, but was not reported in enough detail to allow pooled analysis. Meta regression analysis assessing the relationship between length of follow-up 
and incidence of recurrence appeared to show a relationship, but this was not statistically significant (Figure 7). There was no statistical evidence of publication bias (Egger's test $\mathrm{p}=0.889)$.

\section{Off-midline primary closure}

Nine studies reported the outcomes of off-midline primary closure for a total of 199 patients (including modified Limberg flap [2,8,21,28,32,33], Karydakis [2,8,21,27] and Bascom cleft lift $[8,20,34])$. Three studies reported the outcomes of off-midline closure alone [32-34], 5 compared it to midline primary closure $[2,8,21,27,28], 3$ compared it to open healing [2,20,21], and 1 compared it to minimally invasive techniques [8]. Overall pooled risk of recurrence rate for excision and off-midline primary closure is $6 \%(1-15 \%)$ (Figure 8$)$. When analysed as a subgroup, studies with median follow-up of over 12 months had a pooled risk of recurrence of $8 \%(0-20 \%)$. There was substantial statistical heterogeneity $\left(I^{2}=67.8 \%\right)$. Wound complications were reported by 8 studies with pooled risk of wound complication of $14 \%(6-25 \%)$ with $\mathrm{I}^{2}$ of $64.81 \%$ (Figure 9). Average time to wound healing was reported by only 1 study and was 27 days. There were insufficient studies to perform meta-regression or statistical analysis of publication bias.

\section{Excision + Vac therapy}

Two case series reported outcomes of VAC therapy following excision of pilonidal sinus in a total of 29 patients [35,36]. Overall pooled risk of recurrence was $20 \%(0-65 \%)$. There was substantial statistical heterogeneity $\left(\mathrm{I}^{2}=77.5 \%\right)$ (Figure 10). Neither study reported any wound complications. Average time to wound healing ranged from 38 to 72 days, but was not reported in enough detail to allow further statistical analysis. There were insufficient studies to perform meta-regression or statistical analysis of publication bias.

\section{Minimally invasive techniques}

Six studies reported the results of minimally invasive approaches in 150 patients. The three studies reported the outcomes of Endoscopic Pilonidal Sinus Treatment (EPSiT) [12,30,37] 
in 79 patients overall pooled risk of recurrence was $7 \%\left(1-16 \%, l^{2}=24.1 \%\right)$ (Figure 11). There was one study reporting each of minimal incision [38], fibrin glue obliteration [8] and crystallised phenol treatment [13]. Recurrence rates for these procedures were $2.5 \%, 20 \%$ and $28.6 \%$ respectively. Wound complications were reported in 4 studies and ranged from $0 \%$ to $10 \%$. Time to wound healing were reported in all 3 EPSiT studies and ranged from 21 30 days, however there was not sufficient detail reported to allow further statistical analysis. There were insufficient studies to perform meta-regression or statistical analysis of publication bias.

\section{Marsupialisation}

Results of marsupialisation were reported in three studies for a total of 53 patients $[1,31,39]$. All were comparative cohort studies comparing marsupialisation to midline closure and open healing. Overall risk of recurrence was 6\% (0-22\%) (Figure 12). There was substantial statistical heterogeneity $\left(\mathrm{I}^{2}=60.6 \%\right)$. Wound complications were not reported for this procedure. Average time to wound healing was reported in all 3 studies and ranged from 6 to 41 days, but was not reported in sufficient detail to allow further statistical analysis. There were insufficient studies to perform meta-regression or statistical analysis of publication bias.

\section{Discussion}

We found that evidence for the management of paediatric PNS is limited. Only 26 publications reporting the outcomes of the management of paediatric pilonidal sinuses in 1399 patients were identified. All of these studies were of low quality, and the majority had low number of participants, short follow-up periods and were of moderate to severe risk of bias.

Off-midline primary closure, marsupialisation and minimally invasive techniques have the best outcomes for recurrence rates (6-7\%), wound complications (3-14\%) and average time to wound healing (6-41 days). 
Open wound healing and VAC therapy had the worst reported outcomes with pooled risk of recurrence of $26 \%$ and $20 \%$ respectively. They also had the longest reported range of wound healing times (38-92 and 38-72 days respectively) and open healing had the second highest wound complication rate $(21 \%)$.

Midline primary closure has a better pooled risk of recurrence than open healing $(12 \%$ vs $26 \%$ ), and average wound healing rates comparable to marsupialisation and minimally invasive techniques (8-38 days). However, midline primary closure has the highest risk of wound complication (30\%).

In general the results reported for children are worse than those reported in adults. Stauffer et al [5] report recurrence rates for off-midline closure of $1.6 \%$ at 12 months rising to $6.7 \%$ at 10 years in adults. In our study, children with median follow-up of just 25.5 months reported recurrence rates of $8 \%$ following off-midline closure. The results also showed different trends in children. Excision and open healing was found to have the worst pooled risk of recurrence $(26 \%)$ in children, whereas in adults this procedure has the best recurrence rates $(1.5 \%$ at 12 months to $13 \%$ at 5 years [5]). There are several possible explanations for this. Doll et al [15] suggest that PNS in children is often more severe, especially if there is a family history. Furthermore it has been shown that for many other surgical procedures that high volumes improve outcomes [40]. Most of these studies include relatively small numbers of patients and it may be that the low volume of procedures being carried out has an impact on outcomes.

In contrast, our findings that off-midline primary closure had better outcomes than midline primary closure is similar to findings of meta-analysis of PNS treatments in adults $[4,5]$.

Off-midline primary closure, marsupialization and minimally invasive techniques were found to be comparable and have the best outcomes in terms of recurrence, wound complications and time to wound healing in children. With equivalent outcomes the best technique would be the one of these which causes least disruption to the patient, especially as recurrence 
and reoperation is more likely in children [15]. However, there is virtually no objective or subjective data to guide children and their parents in which of these procedures would be best for them.

The reporting of time to return to normal activities and patient satisfaction was poor across all studies. This information is especially important in children who may miss school and opportunities for social integration because of prolonged wound healing problems and appointments for wound dressing. Future studies should collect results of issues identified as being important by patients, including quality of life, time to return to normal activity and cosmesis.

Although there is little data from using novel, minimally invasive techniques in children these may address some of the issues around impact of surgery on schooling and socialisation. Our study has shown these procedure to have a low risk of recurrence and following fibrin glue obliteration of pilonidal sinus children returned to school after an average of just 3 days

[9]. These procedures therefore show great promise as a generalisable treatment for PNS in children.

\section{Limitations:}

Evidence is of poor quality and limited conclusions can therefore be drawn. As there have been no true comparative studies it is not possible to give definite guidance on which technique gives the best result.

There is obvious need for well performed, large, randomised controlled studies to further investigate the optimum treatment of sacrococcygeal PNS in children. It is important that future studies assess operative outcomes including long term recurrence rates, wound complication rates, time to wound healing and return to normal activities. It is equally important that studies assess the effect of techniques on the quality of life and patient satisfaction of the children treated as well as developing specific patient reported outcome 
measures to facilitate informed consent and allow children and their families to choose the best treatment for them.

\section{Conclusion}

Evidence for management of PNS in children is poor. Minimally invasive techniques, offmidline primary closure and marsupialization have the best reported risk of recurrence, wound complications and time to wound healing.

As limited evidence to guide treatment is available the effect of the chosen method on the patient's quality of life should be given equal consideration. Patient counselling and choice should be an important part of choosing the right approach.

Good quality research including randomised control trials is required to establish the best treatment option for PNS in children.

\section{Acknowledgements}

We thank Susan Toft, Clinical Librarian, Royal Derby Hospital for her help with performing the literature searches. 


\section{References}

[1] Nasr A, Ein SH. A pediatric surgeon's 35-year experience with pilonidal disease in a Canadian children's hospital. Can J Surg 2011;54:39-42. doi:10.1503/cjs.028509.

[2] Fike FB, Mortellaro VE, Juang D, Ostlie DJ, St. Peter SD. Experience with pilonidal disease in children. J Surg Res 2011;170:165-8. doi:10.1016/j.jss.2011.02.016.

[3] Allen-Mersh G, Allen-Mersh TG. Pilonidal sinus: finding the right track for treatment $1990 ; 77: 12-132$.

[4] McCallum IJD, King PM, Bruce J. Healing by primary closure versus open healing after surgery for pilonidal sinus: systematic review and meta-analysis. BMJ 2008;336:868-71. doi:10.1136/bmj.39517.808160.BE.

[5] Stauffer VK, Luedi MM, Kauf P, Schmid M, Diekmann M, Wieferich K, et al. Common surgical procedures in pilonidal sinus disease: A meta-analysis, merged data analysis, and comprehensive study on recurrence. Sci Rep 2018;8:3058. doi:10.1038/s41598018-20143-4.

[6] H. Abu Galala, Isam M. A. Salam, Kh K, Salam IM, Abu Samaan KR, El Ashaal YI, Chandran VP, Sabastian M, et al. Treatment of Pilonidal Sinus by Primary Closure with a Transposed Rhomboid Flap Compared with Deep Suturing: a Prospective Randomised Clinical Trial. Eur J Surg 1999;165:468-72.

doi:10.1080/110241599750006721.

[7] Lund JN. Less Is More in the Treatment of Pilonidal Sinus Disease. Dis Colon Rectum 2017;60:e1. doi:10.1097/DCR.0000000000000727.

[8] Smith CM, Jones A, Dass D, Murthi G, Lindley R. Early experience of the use of fibrin sealant in the management of children with pilonidal sinus disease. J Pediatr Surg 2015;50:320-2. doi:10.1016/j.jpedsurg.2014.11.022.

[9] Hardy E, Herrod P, Sian T, Boyd-Carson H, Blackwell J, Lund J, et al. Fibrin glue 
obliteration is safe, effective and minimally invasive as first line treatment for pilonidal sinus disease in children. J Pediatr Surg 2018.

doi:10.1016/J.JPEDSURG.2018.07.024.

[10] Speter C, Zmora O, Nadler R, Shinhar D, Bilik R. Minimal incision as a promising technique for resection of pilonidal sinus in children. J Pediatr Surg 2017;52:1484-7. doi:10.1016/J.JPEDSURG.2017.03.040.

[11] Meinero P, Stazi A, Carbone A, Fasolini F, Regusci L, La Torre M. Endoscopic pilonidal sinus treatment: a prospective multicentre trial. Color Dis 2016;18:0164-70. doi:10.1111/codi.13322.

[12] Esposito C, Izzo S, Turrà F, Cerulo M, Severino G, Settimi A, et al. Pediatric Endoscopic Pilonidal Sinus Treatment, a Revolutionary Technique to Adopt in Children with Pilonidal Sinus Fistulas: Our Preliminary Experience. J Laparoendosc Adv Surg Tech 2017;28:Iap.2017.0246. doi:10.1089/lap.2017.0246.

[13] Ates U, Ergun E, Gollu G, Sozduyar S, Kologlu M, Cakmak M, et al. Pilonidal sinus disease surgery in children: the first study to compare crystallized phenol application to primary excision and closure. J Pediatr Surg 2018;53:452-5. doi:10.1016/J.JPEDSURG.2017.05.012.

[14] Braungart S, Powis M, Sutcliffe JR, Sugarman ID. Improving outcomes in pilonidal sinus disease. J Pediatr Surg 2016;51:282-4. doi:10.1016/J.JPEDSURG.2015.10.076.

[15] Doll D, Matevossian E, Wietelmann K, Evers T, Kriner M, Petersen S. Family History of Pilonidal Sinus Predisposes to Earlier Onset of Disease and a 50\% Long-Term Recurrence Rate. Dis Colon Rectum 2009;52:1610-5. doi:10.1007/DCR.0b013e3181a87607.

[16] Moher D, Liberati A, Tetzlaff J, Altman DG, PRISMA Group. Preferred reporting items 
for systematic reviews and meta-analyses: the PRISMA statement. BMJ 2009;339:b2535. doi:10.1136/BMJ.B2535.

[17] M O, Hammady H, Fedorowicz Z, Elmagarmid A. Rayyan- a web and mobile app for systematic reviews. Syst Rev 2016;5:210.

[18] Sterne JA, Hernán MA, Reeves BC, Savović J, Berkman ND, Viswanathan M, et al. ROBINS-I: a tool for assessing risk of bias in non-randomised studies of interventions. BMJ 2016;355:i4919. doi:10.1136/BMJ.14919.

[19] Hunter JP, Saratzis A, Sutton AJ, Boucher RH, Sayers RD, Bown MJ. In metaanalyses of proportion studies, funnel plots were found to be an inaccurate method of assessing publication bias. J Clin Epidemiol 2014;67:897-903.

[20] Gendy AS, Glick RD, Hong AR, Dolgin SE, Soffer SZ, Landers H, et al. A comparison of the cleft lift procedure vs wide excision and packing for the treatment of pilonidal disease in adolescents. J Pediatr Surg 2011;46:1256-9.

doi:10.1016/J.JPEDSURG.2011.03.062.

[21] Zagory JA, Golden J, Holoyda K, Demeter N, Nguyen NX. Excision and primary closure may be the better option in the surgical management of pilonidal disease in the pediatric population. Am Surg 2016;82:964-7.

[22] Lukish JR, Kindelan T, Marmon LM, Pennington M, Norwood C. Laser epilation is a safe and effective therapy for teenagers with pilonidal disease. J Pediatr Surg 2009;44:282-5. doi:10.1016/j.jpedsurg.2008.10.057.

[23] Arda IS, Güney LH, Sevmiş Ş, Hiçsönmez A. High Body Mass Index as a Possible Risk Factor for Pilonidal Sinus Disease in Adolescents. World J Surg 2005;29:469_ 71. doi:10.1007/s00268-004-7533-y.

[24] Mutus HM, Aksu B, Uzun E, Gulcin N, Gercel G, Ozatman E, et al. Long-term analysis of surgical treatment outcomes in chronic pilonidal sinus disease. J Pediatr Surg 
2018;53:293-4. doi:10.1016/j.jpedsurg.2017.11.031.

[25] Gonzalez-Temprano N, Sanchez-Vazquez M, Ayuso-Gonzalez L, Pison-Chacon J, Perez-Martinez A. [Are we correctly treating pilonidal disease in children? therapeutic goals beyond preventing recurrence]. Estamos Tratando Bien La Enferm Pilonidal En Los Ninos? Objet Ter Mas Alla Prev La Recidiv 2011;24:161-4.

[26] Serour F, Somekh E, Krutman B, Gorenstein A. Excision with primary closure and suction drainage for pilonidal sinus in adolescent patients. Pediatr Surg Int 2002;18:159-61. doi:10.1007/s003830100683.

[27] Morden P, Geiger JD, Drongowski RA, Teitelbaum DH, Hirschl RB. Comparison of Karydakis versus midline excision for treatment of pilonidal sinus disease. Pediatr Surg Int 2005;21:793-6. doi:http://dx.doi.org/10.1007/s00383-005-1543-1.

[28] Yildiz T, Ilce Z, Kücük A. Modified Limberg flap technique in the treatment of pilonidal sinus disease in teenagers. J Pediatr Surg 2014;49:1610-3. doi:10.1016/j.jpedsurg.2014.06.011.

[29] Ozcan R, Hüseynov M, Bakır AC, Emre S, Tütüncü C, Celayir S, et al. Which treatment modality for pediatric pilonidal sinus: Primary repair or secondary healing? Asian J Surg 2018;41:506-10. doi:10.1016/j.asjsur.2017.08.006.

[30] Sequeira JB, Coelho A, Marinho AS, Bonet B, Carvalho F, Moreira-Pinto J. Endoscopic pilonidal sinus treatment versus total excision with primary closure for sacrococcygeal pilonidal sinus disease in the pediatric population. J Pediatr Surg 2018;53:2003-7. doi:10.1016/j.jpedsurg.2018.02.094.

[31] Lee SL, Tejirian T, Abbas MA. Current management of adolescent pilonidal disease. J Pediatr Surg 2008;43:1124-7. doi:10.1016/J.JPEDSURG.2008.02.042.

[32] Afşarlar ÇE, Yılmaz E, Karaman A, Karaman I, Özgüner IF, Erdoğan D, et al. Treatment of adolescent pilonidal disease with a new modification to the Limberg flap: 
Symmetrically rotated rhomboid excision and lateralization of the Limberg flap technique. J Pediatr Surg 2013;48:1744-9. doi:10.1016/J.JPEDSURG.2013.01.029.

[33] Yamout SZ, Caty MG, Lee Y-HH, Lau ST, Escobar MA, Glick PL. Early experience with the use of rhomboid excision and Limberg flap in 16 adolescents with pilonidal disease. J Pediatr Surg 2009;44:1586-90. doi:10.1016/j.jpedsurg.2008.11.033.

[34] Umesh V, Sussman RH, Smith J, Whyte C. Long term outcome of the Bascom cleft lift procedure for adolescent pilonidal sinus. J Pediatr Surg 2018;53:295-7. doi:10.1016/j.jpedsurg.2017.11.036.

[35] Bütter A, Emran M, Al-Jazaeri A, Ouimet A. Vacuum-assisted closure for wound management in the pediatric population. J Pediatr Surg 2006;41:940-2. doi:10.1016/J.JPEDSURG.2006.01.061.

[36] Caniano DA, Ruth B, Teich S. Wound management with vacuum-assisted closure: experience in 51 pediatric patients. J Pediatr Surg 2005;40:128-32. doi:10.1016/J.JPEDSURG.2004.09.016.

[37] Pini Prato A, Mazzola C, Mattioli G, Escolino M, Esposito C, D’Alessio A, et al. Preliminary report on endoscopic pilonidal sinus treatment in children: results of a multicentric series. Pediatr Surg Int 2018;34:687-92. doi:10.1007/s00383-018-4262-0.

[38] Speter C, Zmora O, Nadler R, Shinhar D, Bilik R. Minimal incision as a promising technique for resection of pilonidal sinus in children. J Pediatr Surg 2017;52:1484-7. doi:10.1016/j.jpedsurg.2017.03.040.

[39] Rouch JD, Keeley JA, Scott A, Sydorak R, DeUgarte D, Lee SL. Short- and long-term results of unroofing and marsupialization for adolescent pilonidal disease. JAMA Surg 2016;151:877-9. doi:10.1001/jamasurg.2016.0850.

[40] Aquina CT, Probst CP, Becerra AZ, lannuzzi JC, Kelly KN, Hensley BJ, et al. High volume improves outcomes: The argument for centralization of rectal cancer surgery. 
Surgery 2016;159:736-48. doi:10.1016/j.surg.2015.09.021. 


\section{Legends for figures}

Figure 1. PRISMA flow diagram

Figure 2. Risk of recurrence following excision and open healing

Figure 3. Risk of wound complications following excision and open healing

Figure 4. Meta-regression analysis of length of follow-up vs recurrence rate for open wound healing

Figure 5. Risk of recurrence following midline primary closure

Figure 6. Risk of wound complications following midline primary closure

Figure 7. Meta-regression analysis of length of follow-up vs recurrence rate for midline primary closure

Figure 8. Risk of recurrence following off-midline primary closure

Figure 9. Risk of wound complications following off-midline primary closure

Figure 10. Risk of recurrence following VAC therapy

Figure 11. Risk of recurrence following EPSiT

Figure 12. Risk of recurrence following Marsupialisation 
Table 1: Characteristics of included studies

\begin{tabular}{|c|c|c|c|c|c|c|c|c|c|c|}
\hline Paper & Year & Country & $\begin{array}{c}N \\
\text { (total) }\end{array}$ & $\begin{array}{l}\text { Median } \\
\text { age } \\
\text { (years) }\end{array}$ & $\begin{array}{r}\mathrm{Ge} \\
\text { Male }\end{array}$ & $\begin{array}{l}\text { Female } \\
\text { Fem }\end{array}$ & Procedure & $n$ & Outcome reported & $\begin{array}{l}\text { Average } \\
\text { follow up } \\
\text { (months) }\end{array}$ \\
\hline Afsarlar et al & 2013 & Turkey & 15 & 14 & 8 & 7 & Off midline primary closure & 15 & $\begin{array}{l}\text { Recurrence, complications, length } \\
\text { drain in situ, length of stay }\end{array}$ & 4 \\
\hline Arda et al & 2005 & Turkey & 14 & 15.4 & 12 & 2 & Midline primary closure & 14 & Recurrence, complications & 3 \\
\hline \multirow[t]{2}{*}{ Ates et al } & \multirow[t]{2}{*}{2018} & \multirow[t]{2}{*}{ Turkey } & \multirow[t]{2}{*}{117} & \multirow[t]{2}{*}{15.6} & \multirow[t]{2}{*}{65} & \multirow[t]{2}{*}{52} & $\begin{array}{l}\text { Minimally Invasive } \\
\text { (Crystallized phenol) }\end{array}$ & 40 & \multirow[t]{2}{*}{$\begin{array}{l}\text { Recurrence, complications, need for } \\
\text { IV analgesia }\end{array}$} & 8.1 \\
\hline & & & & & & & Midline primary closure & 77 & & 44.6 \\
\hline $\begin{array}{l}\text { Braungart et } \\
\text { al }\end{array}$ & 2016 & UK & 19 & 15 & 9 & 10 & Midline primary closure & 19 & Recurrence, complications & 13 \\
\hline Butter et al & 2006 & Canada & 8 & NR & NR & NR & Excision + VAC & 8 & Recurrence, time to wound closure & Not reported \\
\hline Caniano et al & 2005 & USA & 21 & 16 & NR & NR & Excision + VAC & 21 & Recurrence, complications & Not reported \\
\hline Eposito et al & 2017 & Italy & 15 & 16 & 9 & 6 & $\begin{array}{l}\text { Minimally invasive } \\
\text { (Endoscopic) } \\
\text { Open healing }\end{array}$ & $\begin{array}{l}15 \\
15\end{array}$ & $\begin{array}{l}\text { Recurrence. wound healing, pain, } \\
\text { length of stay, patient satisfaction }\end{array}$ & 6 \\
\hline \multirow[t]{3}{*}{ Fike et al } & \multirow[t]{3}{*}{2011} & \multirow[t]{3}{*}{ USA } & \multirow[t]{3}{*}{120} & \multirow[t]{3}{*}{14.9} & \multirow[t]{3}{*}{50} & \multirow[t]{3}{*}{70} & Midline primary closure & 74 & \multirow{3}{*}{$\begin{array}{l}\text { Recurrence, wound breakdown, no. } \\
\text { of follow up visits }\end{array}$} & \multirow[t]{3}{*}{ Not reported } \\
\hline & & & & & & & Off midline primary closure & 18 & & \\
\hline & & & & & & & Other (not well defined) & 21 & & \\
\hline \multirow[t]{2}{*}{ Gendy et al } & \multirow[t]{2}{*}{2011} & \multirow[t]{2}{*}{ USA } & \multirow[t]{2}{*}{70} & \multirow[t]{2}{*}{16} & \multirow[t]{2}{*}{49} & \multirow[t]{2}{*}{21} & Off midline primary closure & 39 & \multirow{2}{*}{$\begin{array}{l}\text { Recurrence, complications, primary } \\
\text { wound healing incidence }\end{array}$} & 19 \\
\hline & & & & & & & Open healing & 37 & & 45 \\
\hline $\begin{array}{l}\text { Gonzales et } \\
\mathrm{al}\end{array}$ & 2011 & Spain & 20 & 13.3 & 5 & 15 & Midline primary closure & 20 & Recurrence, length of stay & Not reported \\
\hline \multirow[t]{2}{*}{ Lee et al } & \multirow[t]{2}{*}{2008} & \multirow[t]{2}{*}{ USA } & \multirow[t]{2}{*}{26} & \multirow[t]{2}{*}{16.7} & \multirow[t]{2}{*}{13} & \multirow[t]{2}{*}{13} & Marsupialisation & 17 & \multirow{2}{*}{$\begin{array}{l}\text { Recurrence, Time to wound closure, } \\
\text { re-operative rate }\end{array}$} & \multirow[t]{2}{*}{6.4} \\
\hline & & & & & & & Primary closure (unspecified) & 9 & & \\
\hline Lukish et al & 2009 & USA & 28 & 17.2 & 17 & 11 & Midline primary closure & 17 & Recurrence & 24.2 \\
\hline
\end{tabular}




\begin{tabular}{|c|c|c|c|c|c|c|c|c|c|c|}
\hline & & & & & & & Open healing & 8 & & \\
\hline \multirow[t]{2}{*}{ Morden et la } & 2005 & USA & 68 & 13.8 & 30 & 38 & Off midline primary closure & 24 & \multirow[t]{2}{*}{ Recurrence, complications } & \multirow[t]{2}{*}{49.4} \\
\hline & & & & & & & Midline primary closure & 44 & & \\
\hline Mutus et al & 2018 & Turkey & 268 & 146 & 146 & 122 & Midline primary closure & 268 & Recurrence, complications & Not reported \\
\hline \multirow[t]{3}{*}{ Nasr et al } & 2011 & Canada & 121 & 15 & 64 & 57 & Open healing & 90 & \multirow[t]{3}{*}{ Recurrence, time to healing } & \multirow[t]{3}{*}{1.2} \\
\hline & & & & & & & Midline primary closure & 4 & & \\
\hline & & & & & & & Marsupialisation & 13 & & \\
\hline \multirow[t]{2}{*}{ Ozcan et al } & 2017 & Turkey & 47 & 15.6 & 22 & 25 & Open healing & 11 & \multirow{2}{*}{$\begin{array}{l}\text { Recurrence, length of stay, recovery } \\
\text { time }\end{array}$} & \multirow[t]{2}{*}{43.2} \\
\hline & & & & & & & Midline primary closure & 36 & & \\
\hline Prato et al & 2018 & Italy & 43 & 15 & 20 & 23 & $\begin{array}{l}\text { Minimally invasive } \\
\text { (Endoscopic) }\end{array}$ & 43 & $\begin{array}{l}\text { Recurrence, length of procedure, } \\
\text { length of stay, reoperation rate }\end{array}$ & 4 \\
\hline \multirow[t]{2}{*}{ Rouch et al } & 2016 & USA & 39 & 16 & 19 & 20 & Other (not well defined) & 16 & \multirow{2}{*}{$\begin{array}{l}\text { Recurrence, time to healing, re- } \\
\text { operation }\end{array}$} & \multirow[t]{2}{*}{ Not reported } \\
\hline & & & & & & & Marsupialisation & 23 & & \\
\hline \multirow[t]{2}{*}{$\begin{array}{l}\text { Sequeira et } \\
\text { al }\end{array}$} & 2018 & Portugal & 84 & 16.2 & 61 & 23 & $\begin{array}{l}\text { Minimally Invasive } \\
\text { (Endoscopic) }\end{array}$ & 21 & \multirow[t]{2}{*}{$\begin{array}{l}\text { Recurrence, complications, healing } \\
\text { time, }\end{array}$} & \multirow[t]{2}{*}{11.9} \\
\hline & & & & & & & Midline primary closure & 63 & & \\
\hline Serour et al & 2002 & Israel & 34 & 16.4 & 20 & 14 & Midline primary closure & 34 & Recurrence, complications & 36 \\
\hline \multirow[t]{3}{*}{ Smith et al } & 2015 & UK & 41 & 15 & 22 & 19 & $\begin{array}{l}\text { Minimally invasive } \\
\text { (Fibrin glue obliteration) }\end{array}$ & 10 & \multirow[t]{3}{*}{$\begin{array}{l}\text { Recurrence, wound dehiscence } \\
\text { incidence }\end{array}$} & \multirow[t]{3}{*}{32} \\
\hline & & & & & & & Midline primary closure & 5 & & \\
\hline & & & & & & & Off midline primary closure & 26 & & \\
\hline \multirow[t]{2}{*}{ Speter et al } & 2017 & Israel & 42 & & 30 & 12 & $\begin{array}{l}\text { Minimally invasive } \\
\text { (Minimal incision) }\end{array}$ & 21 & \multirow{2}{*}{$\begin{array}{l}\text { Recurrence, postoperative } \\
\text { functional outcome, Reoperation } \\
\text { rate }\end{array}$} & 28 \\
\hline & & & & & & & Other (not well defined) & 21 & & 50 \\
\hline Umesh et al & 2018 & USA & 22 & 16 & 18 & 4 & Off midline primary closure & 22 & $\begin{array}{l}\text { Recurrence, complications, healing } \\
\text { time, reoperation rate, patient } \\
\text { satisfaction }\end{array}$ & 44 \\
\hline
\end{tabular}




\begin{tabular}{|c|c|c|c|c|c|c|c|c|c|c|}
\hline Yamout et al & 2009 & USA & 16 & 16 & 9 & 7 & Off midline primary closure & 54 & Recurrence, complications & 11 \\
\hline \multirow[t]{2}{*}{ Yildiz et al } & \multirow[t]{2}{*}{2014} & \multirow[t]{2}{*}{ Turkey } & \multirow[t]{2}{*}{40} & \multirow[t]{2}{*}{15.2} & \multirow[t]{2}{*}{18} & \multirow[t]{2}{*}{22} & Midline primary closure & 8 & \multirow[t]{2}{*}{ Complications, recurrence } & \multirow[t]{2}{*}{5} \\
\hline & & & & & & & Off midline primary closure & 32 & & \\
\hline \multirow[t]{3}{*}{ Zagory et al } & \multirow[t]{3}{*}{2016} & \multirow[t]{3}{*}{ USA } & \multirow[t]{3}{*}{60} & \multirow[t]{3}{*}{15} & \multirow[t]{3}{*}{25} & \multirow[t]{3}{*}{35} & Open healing & 17 & \multirow{3}{*}{$\begin{array}{l}\text { Recurrence, complication, length of } \\
\text { stay, re-operation rate }\end{array}$} & \multirow[t]{3}{*}{53.8} \\
\hline & & & & & & & Midline primary closure & 36 & & \\
\hline & & & & & & & Off midline primary closure & 7 & & \\
\hline
\end{tabular}


Table 2: Risk of bias

\begin{tabular}{|c|c|c|c|c|c|c|c|c|}
\hline Study & $\begin{array}{l}\text { Confoundin } \\
\text { g }\end{array}$ & Selection & $\begin{array}{l}\text { Classification } \\
\text { of Intervention }\end{array}$ & $\begin{array}{l}\text { Deviation from intended } \\
\text { intervention }\end{array}$ & $\begin{array}{l}\text { Missing } \\
\text { Data }\end{array}$ & $\begin{array}{l}\text { Measurement } \\
\text { of Outcomes }\end{array}$ & $\begin{array}{l}\text { Reported } \\
\text { Result }\end{array}$ & Overall \\
\hline Afsarlar (2013) & Moderate & Low & Low & Low & Low & Moderate & Moderate & Moderate \\
\hline Arda (2005) & Moderate & Low & Low & Low & Low & Moderate & Moderate & Moderate \\
\hline Ates (2018) & Serious & Low & Low & Low & Low & Moderate & Moderate & Serious \\
\hline Braungart (2016) & Moderate & Low & Low & Serious & Low & Moderate & Moderate & Serious \\
\hline Butter (2006) & Moderate & Low & Low & Low & Low & Moderate & Moderate & Moderate \\
\hline Caniano (2005) & Moderate & Low & Low & Low & Low & Moderate & Moderate & Moderate \\
\hline Esposito (2017) & Serious & Low & Low & Low & Low & Moderate & Moderate & Serious \\
\hline Fike (2011) & Serious & Serious & Serious & Low & Low & Moderate & Moderate & Serious \\
\hline Gendy (2011) & Serious & Low & Low & Low & Low & Moderate & Moderate & Serious \\
\hline $\begin{array}{l}\text { Gonzalez- } \\
\text { Temprano (2011) }\end{array}$ & Moderate & Low & Low & Low & Low & Moderate & Moderate & Moderate \\
\hline Lee (2008) & Serious & Serious & Low & Low & Low & Moderate & Moderate & Serious \\
\hline Lukish (2009) & Serious & Serious & Low & Low & Low & Moderate & Moderate & Serious \\
\hline Morden (2005) & Serious & Serious & Low & Low & Low & Moderate & Moderate & Serious \\
\hline Mutus (2018) & Moderate & Low & Low & Low & Low & Moderate & Moderate & Moderate \\
\hline Nasr (2011) & Serious & Moderate & Low & Low & Low & Moderate & Moderate & Serious \\
\hline Ozcan (2017) & Moderate & Low & Low & Low & Low & Moderate & Moderate & Moderate \\
\hline Prato (2018) & Moderate & Low & Low & Low & Low & Moderate & Moderate & Moderate \\
\hline Rouch (2016) & Moderate & Serious & Low & Low & Low & Moderate & Moderate & Serious \\
\hline Sequeira (2018) & Moderate & Serious & Low & Low & Moderate & Moderate & Moderate & Serious \\
\hline Serour (2002) & Moderate & Low & Low & Low & Low & Moderate & Moderate & Moderate \\
\hline Smith (2015) & Moderate & Serious & Low & Low & Low & Moderate & Moderate & Serious \\
\hline Speter (2017) & Serious & Low & Serious & Low & Moderate & Moderate & Moderate & Serious \\
\hline Umesh (2018) & Moderate & Moderate & Low & Low & Moderate & Moderate & Moderate & Moderate \\
\hline Yamout (2009) & Moderate & Serious & Low & Low & Low & Moderate & Moderate & Serious \\
\hline Yildiz (2014) & Serious & Low & Low & Low & Low & Moderate & Moderate & Serious \\
\hline Zagory (2016) & Serious & Serious & Low & Low & Low & Moderate & Moderate & Serious \\
\hline
\end{tabular}


Table 3: Summary of results

\begin{tabular}{|c|c|c|c|c|c|c|c|}
\hline \multirow{2}{*}{ Procedure } & \multirow{2}{*}{$\begin{array}{l}\text { No of } \\
\text { studies }\end{array}$} & \multirow{2}{*}{$\begin{array}{l}\text { Total No } \\
\text { of patients }\end{array}$} & \multicolumn{2}{|l|}{ Recurrence } & \multicolumn{2}{|c|}{ Wound complications } & \multirow{2}{*}{$\begin{array}{l}\text { Wound Healing } \\
\text { Range (median values } \\
\text { days) }\end{array}$} \\
\hline & & & $\begin{array}{l}\text { Pooled risk } \\
(\%)\end{array}$ & $\begin{array}{l}95 \% \mathrm{Cl} \\
(\%)\end{array}$ & Pooled risk (\%) & $95 \% \mathrm{Cl}(\%)$ & \\
\hline Open Healing & 6 & 191 & 26 & $15-38$ & 21 & $9-36$ & $38-92$ \\
\hline $\begin{array}{l}\text { Midline Primary } \\
\text { closure }\end{array}$ & 16 & 728 & 12 & $8-18$ & 30 & $19-42$ & $8-38$ \\
\hline $\begin{array}{l}\text { Off-midline primary } \\
\text { closure }\end{array}$ & 9 & 199 & 6 & $1-15$ & 14 & $6-25$ & 27 \\
\hline Excision and VAC & 2 & 29 & 20 & $0-65$ & Not reported & Not reported & $38-72$ \\
\hline $\begin{array}{l}\text { Minimally Invasive } \\
\text { Techniques }\end{array}$ & 6 & 150 & 7 & $1-16$ & Not reported & Not reported & $21-30$ \\
\hline Marsupialisation & 3 & 53 & 6 & $0-22$ & Not reported & Not reported & $6-41$ \\
\hline
\end{tabular}

